\title{
Dental Tourism: A Review
}

\section{RAVNEET SANDHU}

Dental tourism, popularly known as dental holidays is a part of medical tourism and involves those individuals who seek dental care outside their local healthcare systems while vacationing. As the dental tourism is growing worldwide, India has also become a tourist spot for dental patients because of its cost effective and excellent treatment procedures. But there are still many issues faced by the people in order to reap benefits from this sector. The government plays a crucial in eradicating the complexities associated with the process for example simplifying the process of medical visa and instituting visa-on-arrival for patient's so as to further the promotion of the dental services to the visitors.

KEYWORDS: Dental care, Dental tourism, Cost, Treatment, Health

\section{INTRODUCTION}

In today's date with advances in every field and day to day activities, mobility of the patient became a pivotal concern in health policies. Patients are seeking treatments across borders and Internet sites are offering these services. Among medical tourism dental care is one of the areas where it has become exclusively prominent. ${ }^{1}$

Many people are utilizing the preventive and curative services on a regular basis but some of them are seeking their dental care beyond the boundaries of their local healthcare systems while they are travelling. This kind of search for treatment modalities lead to the birth of dental tourism and dental care is one of the areas where medical care tourism has become particularly

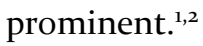

Provision of dental care at significantly low cost in developing countries than the developed world is being rendered by growing dental tourism as the world becomes ever more interdependent and competitive. It's a new and emerging phenomenon where patients, mainly from Europe, North America and Australia, travel abroad for dental treatment. ${ }^{3}$ Cross-border dental care: During the early 1990s patients crossed the border for provision of dental care from neighbouring regions and cross border dental care originated. This further brought a drastic improvement in patient turnover and it was first started in Hungary. Initially it was limited to the neighbouring countries like Austria and gradually Budapest became the second most significant country in dental tourism. India isn't far behind in the league, given its rich culture and pristine beauty has helped it gain popularity for dental tourism as well. Today, dental tourism has a 20-year tradition in Hungary and cross border dental care is widely seen as reliable. ${ }^{4,5}$

Dental Tourism: Dental Tourism means travelling abroad for affordable, accessible dental care, dental treatment, dental surgery or dental procedures, which are generally high priced in one's own country. ${ }^{3}$ This trend was started because of rapidly advancing sky-rocketing costs of healthcare. Long appointments and never ending waiting lists in the western world aided in gaining momentum for this phenomenon. Despite vigorous debates on dental tourism, still scientific studies regarding this phenomenon are lacking.

Driving forces for dental tourism: High costs with insurance premiums, increasing number of un-insured and under insured people in developed nations, longer waiting period in the home country are some of the factors that push the patients to the other countries. Moreover, high availability of better health care services at affordable rate in developing countries, cheaper air fares, and tourism aspect add to the benefits of the outbound dental tourism.

In the recent years, many Europeans and Americans are preferring dental tourism particularly due to savings associated with the low cost for dental services like root canals, veneers, 
fillings, crowns, dental bridges, dental implants, orthodontic care, etc. in the destination countries 6,7

The other less popular factors include reduced waiting time for those patients who seek cosmetic dental treatments. The patients in the United Kingdom choose a trip abroad for a quick-fix smile in case of cosmetic dental treatments. ${ }^{5}$

Lucrative marketing strategies for dental tourism trip include staying at the best and cheap accommodation services, flights and pick up-drop services etc have been commonly used by the many of the destination countries to tempt the patients. ${ }^{6}$

Dental Tourism in worldwide: Mexico followed by India and Hungary is the leading destination in dental tourism as $25 \%$ of the worldwide dental tourists are coming from Mexico and European patients are served by the Hungary, while India attends mostly Asian patients, along with some US citizens. ${ }^{8}$ Even Thailand was also the part of a government plan because of affordable prices for quality dental services than Romania.,910

\section{DENTAL TOURISM IN INDIA}

India is a hub of many international dental clinics and since 20 years it is serving tourists mostly from US, UK and other European countries. Famous for its yoga and meditation, India is now catering to tourist's smiles as well. In India, the Doaba region has lured the largest number of patients to its private dental clinics.

India has globally become an attractive dental tourism destination because of its high standards and cost-effective prices. The most common and sought after dental treatments include root canals, veneers, fillings, crowns, dental bridges, dental implants and tooth whitening, all of which cost much less in India. ${ }^{5}$

There are various advantages in the field of medicine in India like cost effective treatment along with high international standards and wellequipped hospitals. In case of communication also, mostly Indian doctors and other medical staff are fluent in English which is common connecting language globally." Moreover India has various exotic tourist spots which can boost the country's tourism and business. It not only benefits the patient but the country's economy as well and with little help from the government it can be taken to remarkable levels.

Affordable dental care with less waiting time: Affordable prices with good quality dental services, highly specialized staff, shorter dental treatment periods with latest devices of medical technology and equipment are the main advantages of dental tourism. In a study conducted by Piazolo $\mathrm{M}$ et al in 2011 it was found that cost for dental procedure in India is less than USA and hungary is less than Germany. ${ }^{12}$ Naik NTK et al in 2013 in his study found that India is not only cheaper in provision treatment but the waiting time is also almost nil as there are number of private dental sector which comprises of hospitals and clinics exist. ${ }^{13}$

In Hungary dental complication are around 5\%, which was seen in study done by Kovacs $\mathrm{E}$ et al in 2013 which is due to high quality care and dental technology. ${ }^{4}$ Even in Romania dental treatment periods are relatively short and dental offices are highly equipped. ${ }^{10}$

\section{CHALLENGING ISSUES IN DENTAL TOURISM}

Despite it's many advantages, still dental tourism faces many challenges which creates hurdles in the utilization of services by the dental tourist. The low cost of dental treatment in some countries is compromising the quality of dental service, which is the most unethical issue. ${ }^{13}$

Infection control is the another peril for the dental tourist. Proper infection control with standardized methods as well as protection for patients should be the priority for the dentists. But in some countries dental care is not giving the assurance of patient safety or proper infection control. ${ }^{6,14}$

Proper training with technology is highly required in treatment services. But in some of developed or developing countries the standards and quality of dental training is not consistent and uniform. ${ }^{14}$

There are not only treatment related but also ethical and legal issues associated with dental tourism. Due to various advances in every field even legal matters are also area of concern in treatment modalities and we all know that for the dental tourists, patient autonomy with well 
prepared informed consent is of utmost importance now a days. But because of limited or inappropriate information on websites regarding success rates and the quality and standard of care; informed consent is disrupted in destination facilities. ${ }^{15,16}$

Dental tourism in India is still in the growth phase struggling with several issues and challenges. There is hardly any promotion owing to the lack of governmental participation in this sector with no extra investments on dental health infrastructure. Minimal focus on dental health insurance policies the make it worse for the growth of dental tourism. India is competing with nations rendering quality dental care equipped with ethical and legal righteousness while being backed up and supported by various government initiatives.

\section{RECOMMENDATIONS}

India is a leading nation in dental tourism given it's numerous advantages. It has many internationally accredited hospitals. The doctors and medical staff in India have overcome the language barrier, they articulate well in English. In addition, India has a rich cultural heritage and innumerable tourist attractions. The perfect way to recover from an ailment is to combine quality treatment with a great vacation by breaking away from the monotony of the daily routines and indulge in relaxing. The Indian government has to support the dental care treatment with National Health Schemes at affordable charges for average citizens. Furthermore, the government has to reduce barriers in getting medical visa and instituting visaon-arrival for patients to further promote the dental services to visitors.

\section{CONCLUSION}

Dental tourism has become an important and vast part of the growing medical tourism. Major and drastic differences in prices are playing a key role in determining the decisions of the patients to travel abroad for their teeth. Though this review provides the current aspect of dental tourism. But still dental tourism is in the growth phase of its lifecycle. Further studies are required to truly understand the effect of dental travel on patients and its cost to the health system.

\section{REFERENCES}

1. Osterl A, Baláz P, Delgado J Travelling for teeth: characteristics and perspectives of dental care tourism in Hungary. Bri Dent J 2009; 206: 425428

2. Turner L. Cross-border dental care: 'dental tourism' and patient mobility. Br Dent J 2008; 204: 553-554.

3. http://www. what is dental tourism in India.

4. KovacsE, Szocska1G 'Vacation for your teeth' dental tourists in Hungary from the perspective of Hungarian dentists .Brit Dent J 2013; 215: 415-418

5. http:// www.various India Dental Tourism packages.

6. Ortiz M Is the risk of 'foreign' dental treatment worth the savings? J Am Dent Assoc 2011:34-44

7. http://English.hsmt.hu/site/wpcontent/uploads/2013/o2/final case study web.

8. https://ssl.lu.usi.ch/entityws/Allegati/pdf pub535 4.pdf

9. StanciuAC, CondreaE, Constandache M. Aspects regarding the development of the dental tourism in romania sea - Pract App Sci 2014; II (1):588-597

10. https://ideas.repec.org/a/brc/journl/v23y2013isp 4 20-426. html by E Elena - 2013:420-426

11. http://www. MONOGRAPH 26/2013/ K.R.Shanmugam

12. PiazoloM, ZancaNA Medical Tourism - A Case Study for the USA and India, Germany and Hungary. Acta Polytech Hung 2011;8(1):137-160

13. TurnerL "Dental Tourism": Issues Surrounding Cross-Border Travel for Dental Care . J Canad Dent Assoc 2009;75:117-119

14. Delta Dental of Arizona. Trouble in paradise, The untold story of dental tourism: Dangers and risks of cross-border dentistry; Facts \& issues: Delta Dental of Arizona, 2008.

15. Schneider CE. After autonomy. Wake Forest Law Rev 2006; 41:411- 44.

16. Crooks VA, Turner L, Cohen IG, et al. Ethical and legal implications of the risks of medical tourism for patients: a qualitative study of Canadian health and safety representatives' perspectives. Brit Med J Open 2013;3:1-8. 
Source of support: Nil, Conflict of interest: None declared

Cite this article as:

Sandhu R. Dental Tourism: A Review. Int Healthcare Res J 2018;2(3):55-58. doi: 10.26440/IHRJ/02_03/172

\section{AUTHOR AFFILIATIONS:}

$$
\text { 1. BDS }
$$

Corresponding Author:

Dr. Ravneet Sandhu

BDS

House Number 138, Phase 11,

SAS Nagar

Mohali-160065
For article enquiry/author contact details, e-mail at: manuscriptenquiry.ihrj@gmail.com 